\title{
SURVIVAL AND PERIOPERATIVE MORBIDITY OF TOTALLY LAPAROSCOPIC VERSUS OPEN GASTRECTOMY FOR EARLY GASTRIC CANCER: ANALYSIS FROM A SINGLE LATIN AMERICAN CENTRE
}

\author{
Comparação da sobrevida e morbidade perioperatória da gastrectomia totalmente laparoscópica vs. laparotômica para \\ tratamento do câncer gástrico precoce em um centro latino-americano
}

Enrique NORERO ${ }^{1}$, Catalina VARGAS ${ }^{1}$, Pablo ACHURRA ${ }^{1}$, Marco CERONI ${ }^{1}$, Ricardo MEJIA ${ }^{1}$,

Cristian MARTINEZ ${ }^{1}$,Rodrigo MUÑOZ ${ }^{1}$, Paulina GONZALEZ ${ }^{1}$, Alfonso CALVO' ${ }^{1}$, Alfonso DÍAZ'

\begin{abstract}
How to cite this article: Norero E, Vargas C, Achurra P, Ceroni M, Mejia R, Martinez C, Muñoz R, Gonzalez P, Calvo A, Díaz A. Comparação da sobrevida e morbidade perioperatória da gastrectomia totalmente laparoscópica vs. Laparotômica para tratamento do câncer gástrico precoce em um centro latino-americano. ABCD Arq Bras Cir Dig. 2019;32(1):e1413. DOI: /10.1590/0102-672020180001e1413
\end{abstract}

From the ${ }^{1}$ Esophagogastric Surgery Unit Digestive Surgery Department, Hospital Dr. Sotero del Rio, Pontificia Universidad Católica de Chile, Santiago, Chile.

HEADINGS - Stomach neoplasms Laparoscopy. Morbidity. Gastrectomy.
ABSTRACT - Background: Laparoscopic gastrectomy has numerous perioperative advantages, but the long-term survival of patients after this procedure has been less studied. Aim: To compare survival, oncologic and perioperative outcomes between completely laparoscopic vs. open gastrectomy for early gastric cancer. Methods: This study was retrospective, and our main outcomes were the overall and disease-specific 5-year survival, lymph node count and R0 resection rate. Our secondary outcome was postoperative morbidity. Results: Were included 116 patients (59\% men, age 68 years, comorbidities $73 \%$, BMI 25) who underwent 50 laparoscopic gastrectomies and 66 open gastrectomies. The demographic characteristics, tumour location, type of surgery, extent of lymph node dissection and stage did not significantly differ between groups. The overall complication rate was similar in both groups ( $40 \%$ vs. $28 \%, p=n s)$, and complications graded at least Clavien 2 ( $36 \%$ vs. $18 \%, p=0.03$ ), respiratory ( $9 \%$ vs. $0 \%, p=0.03$ ) and wound-abdominal wall complications ( $12 \%$ vs. $0 \%, p=0.009)$ were significantly lower after laparoscopic gastrectomy. The lymph node count ( 21 vs. 23 nodes; $p=n s)$ and R0 resection rate ( $100 \%$ vs. $96 \% ; p=n s)$ did not significantly differ between groups. The 5 -year overall survival $(84 \%$ vs. $87 \%, p=0.31)$ and diseasespecific survival ( $93 \%$ vs. $98 \%, p=0.20)$ did not significantly differ between the laparoscopic and open gastrectomy groups. Conclusion: The results of this study support similar oncologic outcome and long-term survival for patients with early gastric cancer after laparoscopic gastrectomy and open gastrectomy. In addition, the laparoscopic approach is associated with less severe morbidity and a lower occurrence of respiratory and wound-abdominal wall complications.

\section{Correspondence: \\ Enrique Norero \\ Email:enorero@uc.cl, \\ enorero@yahoo.com}

Financial source: none

Conflict of interest: none

Received for publication: $24 / 07 / 2018$ Accepted for publication: 23/10/2018

DESCRITORES - Neoplasias gástricas. Laparoscopia. Epidemiologia. Gastrectomia
RESUMO - Racional: A gastrectomia laparoscópica tem numerosas vantagens perioperatórias, mas a sobrevivência em longo prazo após este procedimento tem sido menos estudada. Objetivo: Comparar resultados de sobrevivência, oncológica e perioperatória entre a gastrectomia completamente laparoscópica vs. aberta para câncer gástrico precoce. Método: Este estudo foi retrospectivo e os principais resultados foram a sobrevivência global e específica de cinco anos, contagem de linfonodos e taxa de ressecção R0. Resultado secundário foi a morbidade pós-operatória. Resultados: Foram incluídos 116 pacientes (59\% homens, idade 68 anos, comorbidades $73 \%$, IMC 25) que foram submetidos a 50 gastrectomias laparoscópicas e 66 gastrectomias abertas. As características demográficas, a localização do tumor, o tipo de operação, a extensão da dissecção dos linfonodos e do estágio não diferiram significativamente entre os grupos. A taxa geral de complicações foi semelhante em ambos os grupos ( $40 \%$ vs. $28 \%, p=n s)$ e complicações classificadas Clavien 2 ( $36 \%$ vs. $18 \%, p=0,03)$, respiratórias ( $9 \%$ vs. $0 \%, p=0,03)$ e as da parede abdominal $(12 \%$ vs. $0 \%, p=0,009)$ foram significativamente menores após a gastrectomia laparoscópica. A contagem de linfonodos (21 contra 23, p=ns) e a taxa de ressecção RO ( $100 \%$ vs. $96 \%$; $p=n s)$ não diferiram significativamente entre os grupos. A sobrevida global de cinco anos ( $84 \%$ vs. $87 \%, p=0,31$ ) e a sobrevida específica $(93 \%$ vs. $98 \%$, $p=0,20)$ não diferiram significativamente entre os grupos de gastrectomia laparoscópica e aberta. Conclusão: Estes resultados suportam resultados oncológicos similares e sobrevida em longo prazo para pacientes com câncer gástrico precoce após gastrectomia laparoscópica e gastrectomia aberta. Além disso, a abordagem laparoscópica está associada com morbidade menos grave e menor ocorrência de complicações respiratórias e da parede abdominal.

\section{INTRODUCTION}

(cc) BY This is an open-acces article distributed under the terms of the Creative Commons Attribution License.
$\mathrm{S}$ ince the first laparoscopic gastrectomy (LG) was performed in 1994 by Kitano ${ }^{17}$, the application of minimally invasive surgery to treat gastric cancer has exponentially increased ${ }^{3,29}$. Most publications originate from Asian countries ${ }^{15}$, and reports seldom originate from South America ${ }^{23,30}$.

Due to an early diagnosis program associated with our hospital ${ }^{4}$, we have operated on a significant number of patients with EGC over the past decade, and we began 
performing LG for the treatment of EGC ten years ago ${ }^{24}$. The current paper represents our mature single-centre experience in performing gastrectomy for EGC.

The aim of this study was to compare survival and perioperative outcomes between completely laparoscopic and open gastrectomy (OG) for EGC. Our main outcomes were overall and disease-specific survival, lymph node count and R0 resection rate. Our secondary outcome was postoperative morbidity.

\section{METHODS}

The local ethics committee approved the study, and the informed consent of patients was waived because of the retrospective nature of the study.

This study describes a retrospective comparative study that included all consecutive patients treated with gastrectomy for EGC on final pathology at a single centre from 2006 to 2016. Patients who met the inclusion criteria for endoscopic resection were treated by endoscopic submucosal dissection and were excluded from this study ${ }^{6}$. A dedicated nurse prospectively collected the data. The decision between LG and OG was based on surgeon preference and experience. All surgeries were performed by attending surgeons who were experienced in open gastrectomy with a developing learning curve for LG.

The preoperativeevaluation included an upper gastrointestinal endoscopy, biopsy, complete blood count, liver-function tests, electrocardiogram, and nutritional evaluation. Preoperative imaging included a thorax-abdomen-pelvis CT-scan.

Total or distal subtotal gastrectomy was performed depending on tumour location. Lymph node dissection was performed in both groups according to the Japanese guidelines ${ }^{2}$.

\section{Laparoscopic surgical technique}

Our LG technique has been previously described ${ }^{24}$. Briefly a pneumoperitoneum with $\mathrm{CO}_{2}$ at $15 \mathrm{mmHg}$ was established, and six laparoscopic ports and a $30^{\circ}$ scope were utilized. The duodenum is divided using a $60 \mathrm{~mm}$ linear stapler. The oesophagus or the stomach was also divided using a $60 \mathrm{~mm}$ linear stapler, and the surgical specimen was extracted through a $4 \mathrm{~cm}$ suprapubic incision. An intracorporeal mechanical gastrojejunostomy was performed after distal subtotal gastrectomy, and an oesophago-jejunostomy (EJ) was performed with a Roux-en-Y reconstruction using three EJ methods (Hand-sewn 23 cases $^{25}$, orvil 2 cases and lineal stapler 1 case).

\section{Open surgical technique}

Our OG technique has been previously described ${ }^{26}$. Briefly, epidural analgesia was routinely used, and a mid-line laparotomy was utilized. The same vessel-sealing device used in LG was used in open surgery. The stomach was divided using a $60 \mathrm{~mm}$ linear stapler, and the oesophagus was sectioned and prepared for EJ anastomosis. A hand-sewn gastro-jejunostomy or mechanical circular stapler EJ was performed.

In the postoperative period, immediate extubation was favoured, and patients began physical and respiratory therapy as soon as possible. Epidural analgesia was generally maintained for three days in $O G$, and a nasogastric tube was kept in place for 3-5 days after subtotal gastrectomy. An oral contrast study was performed 3-7 days after a total gastrectomy. The patients were discharged when they were able to tolerate a soft diet for $24 \mathrm{~h}$.

All deviations from a normal postoperative course of elective gastrectomy for up to 30 days or during the hospital stay were considered postoperative complications. Readmission was considered for up to 60 postoperative days. The appearance of contrast outside the EJ anastomosis in an oral contrast study or CT-scan or by direct evaluation at reoperation was defined as an EJ leak. The impossibility to advance a standard gastroscope through the anastomosis or the need for endoscopic dilation was defined as EJ stenosis. The need to maintain the nasogastric tube for over 10 days after a subtotal gastrectomy with an output exceeding $200 \mathrm{ml}$ was defined as delayed gastric emptying. Abdominal wall and wound complications were both added as a composite outcome. Respiratory symptoms accompanied by an imaging study with pulmonary infiltrates were defined as pneumonia, whereas pleural effusion was characterized by these observations on imaging studies and required either a pleurocentesis or a pleurostomy. Pneumonia, pleural effusion and respiratory failure were added as composite outcomes. Complications were evaluated according to the Clavien-Dindo classification ${ }^{5}$.

Staging was based on the $7^{\text {th }}$ edition of TNM-AJCC22. The follow-up program consisted of a physical examination, laboratory blood tests, endoscopy, and ultrasonography or computed tomography.

\section{Statistical analyses}

Statistical analyses were performed using SPSS version 22, Inc., Chicago, IL and Minitab 15. Categorical variables are expressed in percentages (\%); quantitative values are expressed as the median (range). The Chi-squared test was used to compare frequencies, and the Mann-Whitney $U$ test was used to compare quantitative values. Survival curves were estimated according to the Kaplan-Meier method. The log-rank test was used to compare survival curves. Patients in the LG group who were converted to open surgery remained in the LG group on an intention-treat-basis. All statistical tests were two-sided, and a $p$ value $<0.05$ was considered significant.

\section{RESULTS}

The study included 116 patients with EGC whose median age was 68 (33-86) years and median BMI was 25 (19-38). Fiftynine percent of the cohort was male, and $73 \%$ of patients had at least one comorbidity. Moreover, $54 \%$ of patients had a previous laparotomy. Fifty patients (43\%) received a LG, and 66 (57\%) patients underwent an OG. The age, sex, BMI, comorbidities, surgical risk score and history of a previous laparotomy and demographic characteristics did not significantly differ between groups (Table 1).

The location of the tumour within the stomach was similar in both groups: in $36 \%$ of patients, the tumour was located in the upper third of the stomach, whereas it was located in the middle third and distal third of the stomach in 32\% and 30\% of patients, respectively (Table 1 ). In $53 \%$ of patients, a total gastrectomy was performed, and $60 \%$ of patients had a D2 lymphadenectomy. The extent of gastrectomy and lymph node dissection did not significantly differ between groups (Table 1). The reconstruction method more frequently employed after a subtotal gastrectomy was a Roux-en-Y in LG (76\%) and Billroth II in OG (64\%) ( $p=0.005$, Table 1).

The median estimated intra-operative bleeding was higher in the OG group (300 ml vs. $100 \mathrm{ml} ; \mathrm{p}=0.038$ ), whereas the operative time was significantly longer in the LG group (250 min vs. 330 min; $p=0.0001$ ) (Table 1). Moreover, four patients (8\%) were converted to open surgery due to the misfiring of the duodenal stapler, central obesity, a cholecystoduodenal fistula, and intestinal malrotation.

The overall rate of postoperative morbidity was 35\%, and the complication rate tended to be lower in the LG group, as demonstrated by a rate of $28 \%$ compared to a rate of $40 \%$ in the OG group; however, this difference was not significant $(p=n s)$. The rates of intrabdominal or medical complications did not significantly differ between groups $(p=n s)$. Wound and abdominal wall complications were significantly lower in the LG group (12\% vs. $0 \% ; p=0.009)$. In the OG group, five patients $(7 \%)$ exhibited abdominal wall dehiscence, and three 
(4\%) developed surgical site infection. Two of the five patients with abdominal wall dehiscence required a re-operation with general anaesthesia to close the abdominal wall. Respiratory complications were also significantly lower in the LG group (9\% vs. $0 \% ; p=0.031$, Table 2 ) and were stratified as follows: $6 \%$ of patients developed pneumonia, $3 \%$ pleural effusion and one patient exhibited respiratory failure in the OG group.

TABLE 1 - Patient demographics and surgery details

\begin{tabular}{|c|c|c|c|}
\hline & $\begin{array}{c}\text { Open } \\
\text { gastrectomy } \\
I(n=66)\end{array}$ & $\begin{array}{l}\text { Laparoscopic } \\
\text { gastrectomy } \\
(n=50)\end{array}$ & $\mathrm{p}$ \\
\hline Age (years) & $69(33-86)$ & $69(38-85)$ & 0.618 \\
\hline Sex (male) & $43(65.2 \%)$ & $26(52.0 \%)$ & 0.153 \\
\hline BMI (kg/mt2) & $23.9(19-38)$ & $26.5(20-32)$ & 0.126 \\
\hline ASA score & & & 0.173 \\
\hline I & $14(21.2 \%)$ & 17 (34.0\%) & \\
\hline II & 39 (59.1\%) & $28(56.0 \%)$ & \\
\hline III & $13(19.7 \%)$ & $5(10.0 \%)$ & \\
\hline Hypertension & $30(45.5 \%)$ & $25(50.0 \%)$ & 0.627 \\
\hline Diabetes & $12(18.2 \%)$ & $6(12.0 \%)$ & 0.362 \\
\hline Cardiac disease & $9(13.6 \%)$ & $5(10.0 \%)$ & 0.552 \\
\hline Stroke & 4 (6.1\%) & $2(4.0 \%)$ & 0.479 \\
\hline Pulmonary disease & $6(9.1 \%)$ & $4(8 \%)$ & 0.555 \\
\hline Chronic liver disease & $2(3.0 \%)$ & $1(2.0 \%)$ & 0.604 \\
\hline Previous laparotomy & $31(50.8 \%)$ & $29(58.0 \%)$ & 0.450 \\
\hline Upper abdominal laparotomy & 20 (32.8\%) & 16 (32.0\%) & 0.930 \\
\hline Tumour location & & & 0.572 \\
\hline Superior & $23(38.3 \%)$ & 17 (34.0\%) & \\
\hline Middle & $21(35.0 \%)$ & $15(30.0 \%)$ & \\
\hline Inferior & $16(26.7 \%)$ & 18 (36.0\%) & \\
\hline Gastrectomy type & & & 0.785 \\
\hline Total & 36 (54.5\%) & $26(52.0 \%)$ & \\
\hline Subtotal distal & $30(45.5 \%)$ & $24(48.0 \%)$ & \\
\hline Lymph node dissection & & & 0.170 \\
\hline D0 & $0(0 \%)$ & $1(2.0 \%)$ & \\
\hline D1 & $8(14.5 \%)$ & $3(6.0 \%)$ & \\
\hline $\mathrm{D} 1+$ & $12(21.8 \%)$ & $18(36.0 \%)$ & \\
\hline D2 & $35(63.6 \%)$ & $28(56.0 \%)$ & \\
\hline $\begin{array}{l}\text { Subtotal gastrectomy } \\
\text { reconstruction }\end{array}$ & & & 0.005 \\
\hline Billroth I & $0(0 \%)$ & 1 (4.8\%) & \\
\hline Billroth II & $16(64.0 \%)$ & $4(19.0 \%)$ & \\
\hline Y Roux & $9(36.0 \%)$ & 17 (76.2\%) & \\
\hline Operative time (min) & $240(120-480)$ & $330(210-510)$ & 0.0001 \\
\hline Operative bleeding (cc) & $300(50-800)$ & $110(10-500)$ & 0.038 \\
\hline
\end{tabular}

In the OG and LG groups, $36 \%$ and $18 \%$ of patients developed complications classified as Clavien 2 or higher, respectively ( $p=0.03$, Table 2$)$. Five required a reoperation; in the OG group, two reoperation because of abdominal wall dehiscence and one due to EJ leak. In the LG group, one patient required reoperation because of an EJ leak and one due to a duodenal stump fistula. The reoperation rate did not significantly differ between groups ( $4.4 \%$ vs. $4 \%, p=n s$, Table 2 ).

The postoperative mortality rate was $2.6 \%$ and was represented by two (3\%) patients in the OG group and one (2\%) in the LG group ( $p=n s$, Table 2$)$. The mortality causes in these three patients were pneumonia associated with postoperative stroke, pulmonary embolism and EJ leak.
TABLE 2 - Postoperative clinical outcome and complications

\begin{tabular}{|c|c|c|c|}
\hline Complications & $\begin{array}{l}\text { Open } \\
\text { gastrectomy } \\
I(n=66)\end{array}$ & $\begin{array}{c}\text { Laparoscopic } \\
\text { gastrectomy } \\
(n=50)\end{array}$ & $\mathrm{p}$ \\
\hline Intrabdominal & $10(15.2 \%)$ & 11 (22.0\%) & 0.343 \\
\hline EJ fistula & $2(5.6 \%)$ & $3(11.5 \%)$ & 0.346 \\
\hline Duodenal fistula & $0(0 \%)$ & $3(6.0 \%)$ & 0.077 \\
\hline Subphrenic abscess & $1(1.5 \%)$ & $1(2.0 \%)$ & 0.678 \\
\hline EJ stenosis & $2(5.6 \%)$ & $0(0 \%)$ & 0.333 \\
\hline Pancreatic fistula & $0(0 \%)$ & $1(0 \%)$ & 0.431 \\
\hline Abdominal bleeding & $1(1.5 \%)$ & $0(0 \%)$ & 0.569 \\
\hline Ileus & $1(1.5 \%)$ & $0(0 \%)$ & 0.569 \\
\hline Delayed gastric emptying & $0(0 \%)$ & $3(12.5 \%)$ & 0.082 \\
\hline Wound - Abdominal wall & $8(12.1 \%)$ & $0(0 \%)$ & 0.009 \\
\hline Dehiscence & 5 (7.6\%) & $0(0 \%)$ & 0.056 \\
\hline Surgical site infection & $3(4.5 \%)$ & $0(0 \%)$ & 0.181 \\
\hline Medical & $11(16.7 \%)$ & $4(8.0 \%)$ & 0.136 \\
\hline Respiratory & $6(9.1 \%)$ & $0(0 \%)$ & 0.031 \\
\hline Pneumonia & $4(6.1 \%)$ & $0(0 \%)$ & 0.101 \\
\hline Pleural effusion & $2(3.0 \%)$ & $0(0 \%)$ & 0.322 \\
\hline Respiratory failure & $1(1.5 \%)$ & 0 (\%) & 0.569 \\
\hline Arrhythmia & $2(3.0 \%)$ & $0(0 \%)$ & 0.322 \\
\hline $\begin{array}{l}\text { Pseudomembranous } \\
\text { colitis1 }(1.5 \%)\end{array}$ & $1(1.5 \%)$ & $2(4.0 \%)$ & 0.396 \\
\hline Urinary tract infection & $2(3.0 \%)$ & $1(2.0 \%)$ & 0.604 \\
\hline Central catheter infection & $1(1.5 \%)$ & $0(0 \%)$ & 0.569 \\
\hline Thromboembolic disease & $2(3.0 \%)$ & $1(2.0 \%)$ & 0.604 \\
\hline Stroke & $1(1.5 \%)$ & $0(0 \%)$ & 0.569 \\
\hline Morbidity & 27 (40.9\%) & $14(28.0 \%)$ & 0.150 \\
\hline Reoperation & $3(4.5 \%)$ & 2 (4\%) & 0.630 \\
\hline Morbidity Clavien $\geq 2$ & $24(36.4 \%)$ & $9(18 \%)$ & 0.030 \\
\hline Morbidity Clavien $\geq 3$ & $9(13.6 \%)$ & $2(4.0 \%)$ & 0.072 \\
\hline Mortality & $2(3.0 \%)$ & $1(2.0 \%)$ & 0.604 \\
\hline Length of stay (days) & $9(5-60)$ & $7(4-37)$ & 0.017 \\
\hline Readmission & $7(10.6 \%)$ & $2(4.0 \%)$ & 0.070 \\
\hline
\end{tabular}

The length of stay was significantly shorter by two days in the LG group ( 9 vs. 7 days, $p=0.017$, Table 2).

Fifty-seven percent of cancers were mucosal cancers, and $43 \%$ exhibited submucosal involvement; these rates did not differ between groups $(p=n s)$. Ninety-four percent of patients were classified as N0 disease, and this rate did not differ between groups $(p=n s)$. Moreover, two (3\%) and five (10\%) patients with T1A and T1B disease, respectively, exhibited lymph node metastases. The median number of lymph nodes resected was similar in the OG and LG groups ( 21 vs. $23 ; p=n s$, and microscopic tumour-free margins were comparable in both groups ( $100 \%$ vs. $96 \%, p=n s$, Table 3$)$. The two patients in the LG group with a positive margin had undergone a subtotal gastrectomy for a large EGC at the beginning of the experience with LG; both patients were converted to a laparoscopic total gastrectomy three months after the initial surgery, and there was no tumour in this second resection.

The median follow up was 59 months. At the end of the study $96(83 \%)$ patients were alive and $20(17 \%)$ patients had died; specifically three (2.5\%) had died of EGC recurrence, two $\mathrm{T} 1 \mathrm{~A}$ and one T1B, and none had lymph node metastases. The overall 5 -year survival rate was $85 \%$ (median not reached), $84 \%$ in the OG group and $87 \%$ in the LG group $(p=0.314$, Figure 1). The disease-specific 5 -year survival was $95 \%$ (median not reached). Disease-specific 5-year survival was $93 \%$ in the OG group and $98 \%$ in the LG group ( $p=0.207$, Figure 2$)$. The log-rank test did not identify differences in the long-term overall survival or in disease-specific survival between the LG and OG groups. 
TABLE 3 - Pathologic staging, lymph node count and margin status

\begin{tabular}{|l|c|c|c|}
\hline \multicolumn{1}{|c}{ Complications } & $\begin{array}{c}\text { Open } \\
\text { gastrectomy } \\
\text { I(n=66) }\end{array}$ & $\begin{array}{c}\text { Laparoscopic } \\
\text { gastrectomy } \\
(\mathbf{n}=50)\end{array}$ & $p$ \\
\hline T & $35(53.0 \%)$ & $31(62.0 \%)$ & 0.334 \\
\hline T1a (mucosa) & $31(47.0 \%)$ & $19(38.0 \%)$ & \\
\hline T1b (submucosa) & $63(95.5 \%)$ & $46(92.0 \%)$ & \\
\hline N & $0(0 \%)$ & $2(4.0 \%)$ & \\
\hline 0 & $2(3.0 \%)$ & $1(2.0 \%)$ & \\
\hline 1 & $1(1.5 \%)$ & $1(2.0 \%)$ & \\
\hline 2 & & & 0.418 \\
\hline 3 & $63(95.5 \%)$ & $46(92.0 \%)$ & \\
\hline Stage & $0(0 \%)$ & $2(4.0 \%)$ & \\
\hline IA & $2(3.0 \%)$ & $1(2.0 \%)$ & \\
\hline IB & $1(1.5 \%)$ & $1(2.0 \%)$ & \\
\hline IIA & $21(1-56)$ & $23(4-103)$ & 0.300 \\
\hline IIB & & & 0.495 \\
\hline Lymph node count & $15(22.7 \%)$ & $11(22.0 \%)$ & \\
\hline Lymph node count & $26(39.4 \%)$ & $24(30.0 \%)$ & \\
\hline 0-14 & $25(37.9 \%)$ & $24(48.0 \%)$ & \\
\hline 15-24 & & & 0.184 \\
\hline 25 or more & $66(100 \%)$ & $48(96.0 \%)$ & \\
\hline Margin status & $0(0 \%)$ & $2(4.0 \%)$ & \\
\hline R0 & & & \\
\hline R1 & & & \\
\hline
\end{tabular}

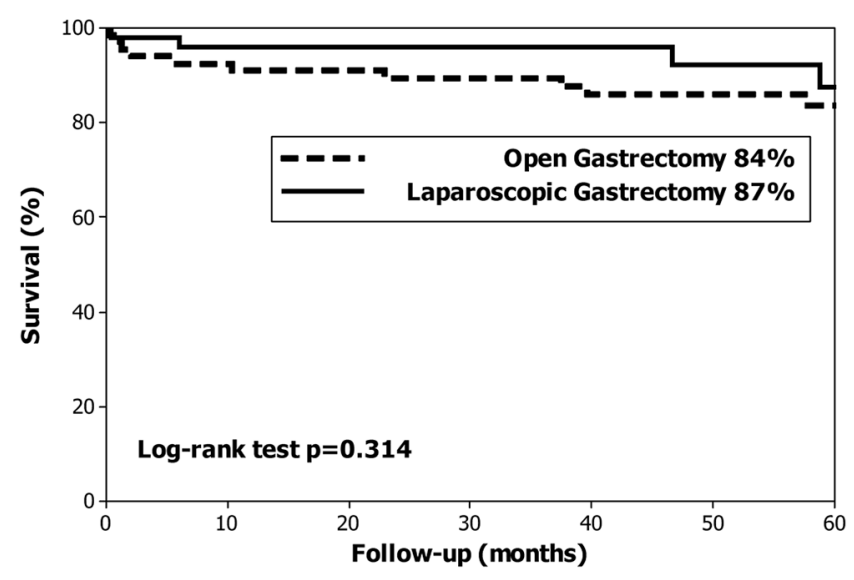

FIGURE1- Overall 5-year survival in patients with early gastric cancer treated with open and laparoscopic gastrectomy

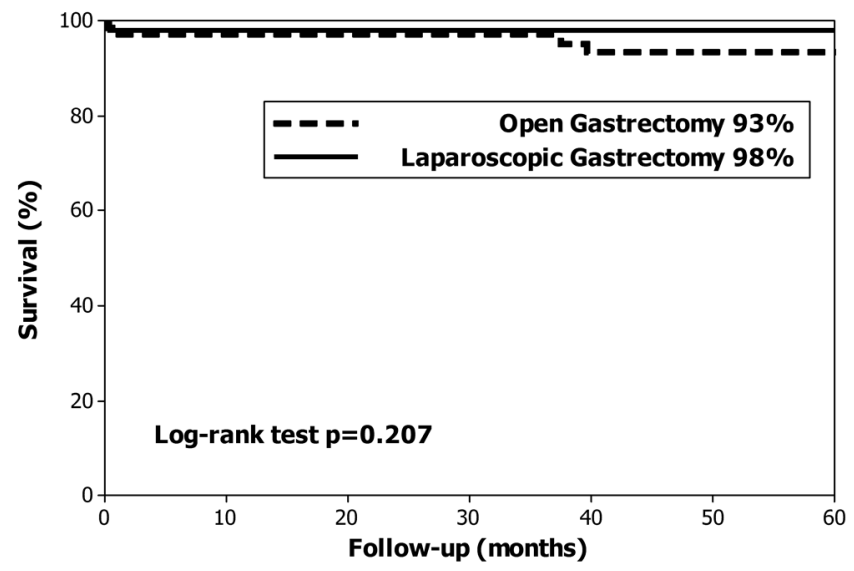

FIGURE 2 - Disease-specific 5-year survival in patients with early gastric cancer treated with open and laparoscopic gastrectomy
The long-term overall survival after surgery for EGC reportedly exceeds $80 \%$, and disease-specific survival exceeds $90 \%$ because most patients die from other diseases. However, most of these data were obtained in studies in which patients underwent $O G^{12,31}$. Despite the fact that the first $L G$ was performed more than two decades ago ${ }^{1}$, controversy still surrounds the use of LG for the treatment of gastric cancer because of the insufficient evidence in favour of its long-term oncologic outcomes.

Most studies comparing LG with OG have included a small number of patients and have focused only on the short-term and perioperative outcomes ${ }^{29}$, such us operative bleeding, operative time and postoperative morbidity ${ }^{8,15}$. Moreover, only a few randomized controlled trials and non-randomized studies have evaluated long-term survival ${ }^{1,9,14,16}$. These studies have demonstrated similar long-term survival for patients with EGC treated with $L G$ or $O G^{1,9,14,16}$. Our study with a significant number of patients and with long-term follow-up supports a similar overall and disease-specific long-term survival.

Between two and $20 \%$ of patients with EGC have lymph node-positive disease ${ }^{1,27}$, making lymph node dissection an essential part of surgery. Most patients in our study had at least a D1+ dissection, and 6\% had lymph node-positive disease. The lymph node count is usually considered an indicator of the completeness of lymph node dissection. In our study, the lymph node count was similar between the LG and OG groups, supporting the feasibility of performing a complete lymphadenectomy with the laparoscopic approach. Previously published results are conflicting, with some studies finding a lower ${ }^{29}$ or similar ${ }^{10,13}$ lymph node count. The $\mathrm{R} 0$ resection rate was the same between groups, $100 \%$ and $96 \%$.

The three oncologic outcomes in this study, lymph node count, R0 resection and overall and disease-specific survival, support the oncologic equivalence of LG and OG for EGC.

Previous studies and meta-analyses indicate that the morbidity rate is lower for $L G$ than $O G^{15,29}$. In our study we could not demonstrate a difference in general morbidity, likely due to the sample size. However, respiratory and wound-abdominal wall complications were significantly lower in the LG group ${ }^{28}$. The reduction in wound-abdominal wall complications may specifically be associated with the totally laparoscopic approach in our study given our median BMI of 25 and the high comorbidity rate, whereas the lower rate of respiratory complications in the LG group may be associated with reduced postoperative pain and the early ambulation described for patients in the LG group ${ }^{18}$. Other studies have found similar lower wound complication rates ${ }^{15}$, better respiratory function results ${ }^{18}$ and lower respiratory complications ${ }^{21}$, supporting our findings.

Only a few studies have evaluated the severity of complications ${ }^{13,16}$. The studies by Kelly ${ }^{13}$ and $\mathrm{Kim}^{16}$ both reported a lower rate of mild complications but an equal frequency of more severe complications. Interestingly, our study identified a lower frequency of moderate-severe complications in the LG group, which has not been reported previously and may be associated with a lower rate of reoperations associated with abdominal wall complications and fewer respiratory complications, possibly due to the totally laparoscopic technique in the LG group.

Most publications describing LG originate in Asia ${ }^{14,15}$. In the West, LG has not been widely adopted and has been developed consistently by only a few expert centres $7,13,20,23,30$. In fact, the applicability of LG has been questioned by our Asian colleagues ${ }^{9}$, but our study supports the applicability of LG in countries outside Asia. Because of the higher BMI and comorbidities, and more common need for total gastrectomy in the west compared to Asia9,14, we hypothesize that the reduction in complications in Western countries may be even 
more pronounced in future studies.

In this study, we included a consecutive and significant number of patients with long-term follow-up. The data were obtained from a prospectively maintained database. Moreover, a contemporary control group was included. According to a score described by a recent meta-analysis evaluating nonrandomized trials of $L G$, our study has a high quality score ${ }^{29}$. Another strength of our study is the severity evaluation of complications with the Clavien score. In addition to these methodological aspects, we employed a totally laparoscopic technique, which has been described to be superior to the laparoscopic assisted method employed in most reported trials ${ }^{11}$.

Some of the limitations of this study are that the decision to perform LG or OG may have been influenced by variables such as surgeon and hospital experience at the time and a preoperative diagnosis of a higher tumour stage, despite the fact that the two groups were well balanced. Moreover, patients with EGC were included in this study on the basis of postoperative pathology and not clinical preoperative evaluation.

\section{CONCLUSION}

The results of this study support a similar oncologic outcome and long-term survival for laparoscopic gastrectomy and open gastrectomy for patients with EGC. In addition, the laparoscopic approach is associated with less severe morbidity and a lower occurrence of respiratory and wound-abdominal wall complications.

REFERENCES

1. An JY, Heo GU, Cheong JH, Hyung WJ, Choi SH, Noh SH. Assessment of open versus laparoscopy-assisted gastrectomy in lymph node-positive early gastric cancer: a retrospective cohort analysis. J Surg Oncol. 2010;102(1):77-81.

2. Association JGC. Japanese gastric cancer treatment guidelines 2014 (ver 4). Gastric Cancer. 2017;20(1):1-19.

3. Calvo A, Pruyas M, Nilsen E, Verdugo P. Population resecar of gastric cancer in digestive symptomatic patients, from 1996 to 2000. Rev Med Chile. 2001:129(7): 749-55.

4. Clavien PA, Barkun J, de Oliveira ML, Vauthey JN, Dindo D, Schulick RD, etal. The Clavien-Dindo classification of surgical complications: five-year experience. Ann Surg. 2009;250(2):187-96.

5. Galindo J, Rodriguez J, Norero E, Aguayo G, Pruyas M, Nilsen E, et al. Endoscopic submucosal dissection for early gastric cancer. Rev Chil Cir. 2015;67(6):590-8.

6. Greenleaf EK, Sun SX, Hollenbeak CS, Wong J. Minimally invasive surgery for gastric cancer: the American experience. Gastric Cancer 2017:20(2):368-78.

7. Hayashi H, Ochiai T, Shimada H, Gunji Y. Prospective randomized study of open versus laparoscopy-assisted distal gastrectomy with extraperigastric lymph node dissection for early gastric cancer. Surg Endosc. 2005;19(9):1172-1176.

8. Honda M, Hiki N, Kinoshita T, Yabusaki H, Abe T, Nunobe S, et al. Longterm Outcomes of Laparoscopic Versus Open Surgery for Clinical Stage I Gastric Cancer: The LOC-1 Study. Ann Surg. 2016;264(2):214-22.

9. Huscher CG, Mingoli A, Sgarzini G, Sansonetti A, Di Paola M, Recher A et al. Laparoscopic versus open subtotal gastrectomy for distal gastric cancer: five-year results of a randomized prospective trial. Ann Surg. 2005;241(2):232-7.

10. Ikeda O, Sakaguchi Y, Aoki Y, Harimoto N, Taomoto J, Masuda T, et al. Advantages of totally laparoscopic distal gastrectomy over laparoscopically assisted distal gastrectomy for gastric cancer. Surg Endosc. 2009;23(10):2374-9.

11. Jentschura D, Heubner C, Manegold BC, Rumstadt B, Winkler M, Trede $M$. Surgery for early gastric cancer: a European one-center experience. World J Surg. 1997;21(8):845-8; discussion 9.
12. KellyKJ,SelbyL,ChouJF, DukleskaK, CapanuM,CoitDG, etal.Laparoscopic Versus Open Gastrectomy for Gastric Adenocarcinoma in the West: A Case-Control Study. Ann Surg Oncol. 2015;22(11):3590-6.

13. Kim HH, Han SU, Kim MC, Hyung WJ, Kim W, Lee HJ, et al. Long-term results of laparoscopic gastrectomy for gastric cancer: a large-scale case-control and case-matched Korean multicenter study. J Clin Oncol. 2014;32(7):627-33.

14. Kim W, Kim HH, Han SU, Kim MC, Hyung WJ, Ryu SW, et al. Decreased Morbidity of Laparoscopic Distal Gastrectomy Compared With Open Distal Gastrectomy for Stage I Gastric Cancer: Short-term Outcomes From a Multicenter Randomized Controlled Trial (KLASS-01). Ann Surg. 2016;263(1):28-35

15. Kim YW, Yoon HM, Yun YH, Nam BH, Eom BW, Baik YH, et al. Long-term outcomes of laparoscopy-assisted distal gastrectomy for early gastric cancer: result of a randomized controlled trial (COACT 0301). Surg Endosc. 2013:27(11):4267-76.

16. Kitano S, Iso Y, Moriyama M, Sugimachi K. Laparoscopy-assisted Billroth I gastrectomy. Surg Laparosc Endosc. 1994;4(2):146-8.

17. KitanoS, Shiraishi N, Fujii K, Yasuda K, Inomata M, AdachiY.A randomized controlled trialcomparingopenvslaparoscopy-assisted distalgastrectomy for the treatment of early gastric cancer: an interim report. Surgery. 2002;131(1 Suppl):S306-11.

18. Kodera Y, Fujiwara M, Ohashi N, Nakayama G, Koike M, Morita S, et al. Laparoscopic surgery for gastric cancer: a collective review with metaanalysis of randomized trials. J Am Coll Surg. 2010;211(5):677-86.

19. Kostakis ID, Alexandrou A, Armeni E, Damaskos C, Kouraklis G, Diamantis T, et al. Comparison Between Minimally Invasive and Open Gastrectomy for Gastric Cancer in Europe: A Systematic Review and Meta-analysis. Scand J Surg. 2017;106(1):3-20.

20. Lee $\mathrm{JH}$, Han HS. A prospective randomized study comparing open vs laparoscopy-assisted distal gastrectomy in early gastric cancer: early results. Surg Endosc. 2005;19(2):168-73.

21. Marrelli D, Morgagni P, de Manzoni G, Coniglio A, Marchet A, Saragoni $L$, et al. Prognostic value of the 7th AJCC/UICC TNM classification of noncardia gastric cancer: analysis of a large series from specialized Western centers. Ann Surg. 2012;255(3):486-91.

22. Moisan F, Norero E, Slako M, Varas J, Palominos G, Crovari F, et al. Completelylaparoscopicversusopengastrectomyforearlyandadvanced gastric cancer: a matched cohort study. Surg Endosc. 2012;26(3):661-72.

23. Norero E, Báez S, Briceño E, Martínez C, Ceroni M, Escalona A, et al. Totally laparoscopic gastrectomy for the treatment of gastric tumors. Rev Med Chil. 2015;143(3):281-8.

24. Norero E, Muñoz R, Ceroni M, Manzor M, Crovari F, Gabrielli M. TwoLayer Hand-Sewn Esophagojejunostomy in Totally Laparoscopic Total Gastrectomy for Gastric Cancer. J Gastric Cancer. 2017;17(3):267-76.

25. Norero E, Vega EA, Diaz C, Cavada G, Ceroni M, Martínez C, et al. Improvement in postoperative mortality in elective gastrectomy for gastric cancer: Analysis of predictive factors in 1066 patients from a single centre. Eur J Surg Oncol. 2017;43(7):1330-1336.

26. Pereira MA, Ramos MFKP, Dias AR, Yagi OK, Faraj SF, Zilberstein $B$ Cecconello I, Mello ES, Ribeiro U Jr. Detection of occult lymph node tumor cells in node-negative gastric cancer patients. Arq Bras Cir Dig. 2017 Jan-Mar;30(1):30-34.

27. Sharma D, Hazrah P, Sattavan S, Ganguly PK, Lal R. Misadventure during laparoscopic sleeve gastrectomy: why it happened? how to prevent and recover from it? Arq Bras Cir Dig. 2016;29Suppl 1(Suppl 1):134-135

28. Viñuela EF, Gonen M, Brennan MF, Coit DG, Strong VE. Laparoscopic versus open distal gastrectomy for gastric cancer: a meta-analysis of randomized controlled trials and high-quality nonrandomized studies. Ann Surg. 2012:255(3):446-56

29. Wada AM, Hashiba K, Otoch JP, Brasil H, Marson FP, Cassab J, Abdalla $R$, Artifon ELA. Full-thickness endoscopic gastric resection using a stapler and gastrostomy: a feasibility study. Arq Bras Cir Dig. 2018 Aug 16;31(3):e1386.

30. Yuasa N, Nimura Y. Survival after surgical treatment of early gastric cancer, surgical techniques, and long-term survival. Langenbecks Arch Surg. 2005:390(4):286-93. 